\title{
Silicanin-1 is a conserved diatom membrane protein involved in silica biomineralization
}

\author{
Alexander Kotzsch', Philip Gröger ${ }^{1}$, Damian Pawolski ${ }^{1}$, Paul H. H. Bomans ${ }^{2,3}$, Nico A. J. M. Sommerdijk ${ }^{2,3}$, \\ Michael Schlierf ${ }^{1}$ and Nils Kröger ${ }^{1,4^{*}}$ (D)
}

\begin{abstract}
Background: Biological mineral formation (biomineralization) proceeds in specialized compartments often bounded by a lipid bilayer membrane. Currently, the role of membranes in biomineralization is hardly understood.

Results: Investigating biomineralization of $\mathrm{SiO}_{2}$ (silica) in diatoms we identified Silicanin-1 ( $\mathrm{Sin} 1$ ) as a conserved diatom membrane protein present in silica deposition vesicles (SDVs) of Thalassiosira pseudonana. Fluorescence microscopy of GFP-tagged Sin 1 enabled, for the first time, to follow the intracellular locations of a biomineralization protein during silica biogenesis in vivo. The analysis revealed incorporation of the N-terminal domain of $\operatorname{Sin} 1$ into the biosilica via association with the organic matrix inside the SDVs. In vitro experiments showed that the recombinant N-terminal domain of Sin 1 undergoes $\mathrm{pH}$-triggered assembly into large clusters, and promotes silica formation by synergistic interaction with long-chain polyamines.

Conclusions: Sin 1 is the first identified SDV transmembrane protein, and is highly conserved throughout the diatom realm, which suggests a fundamental role in the biomineralization of diatom silica. Through interaction with long-chain polyamines, Sin1 could serve as a molecular link by which the SDV membrane exerts control on the assembly of biosilica-forming organic matrices in the SDV lumen.
\end{abstract}

Keywords: Diatom biosilica, Biomineralization vesicles, Transmembrane protein, Vesicle biogenesis, Exocytosis, Time-lapse confocal fluorescence microscopy, Protein self-assembly, Cryo-TEM, Silica formation activity

\section{Background}

Diatoms are unicellular photosynthetic eukaryotes that produce cell walls made of amorphous, hydrated $\mathrm{SiO}_{2}$ (silica) and associated macromolecules $[1,2]$. The diatom cell wall is located extracellular to the plasma membrane and completely encases the protoplast. Like in many other organisms (e.g., radiolaria, coccolithophores, sponges, foraminifers), the biomineral building blocks of diatoms are produced inside the cell in specialized vesicles and subsequently exocytosed and incorporated into the cell wall [3-5]. Diatom cell walls are composed of two different types of nanopatterned porous biosilica

\footnotetext{
* Correspondence: nils.kroeger@tu-dresden.de

${ }^{1} B$ CUBE Center for Molecular Bioengineering, CMCB, TU Dresden,

Arnoldstrasse 18, 01307 Dresden, Germany

${ }^{4}$ Department of Chemistry and Food Chemistry, TU Dresden, 01062 Dresden, Germany

Full list of author information is available at the end of the article
}

building blocks termed girdle bands (ring-shaped silica) and valves (complex shaped silica often with plate-, bowl-, or dome-like structure). During biosilica formation, silica deposition vesicles (SDVs) are positioned at the cytosolic site of the plasma membrane precisely opposite the cell wall region where a new biomineral building block will be integrated. The site-specific assembly of SDVs and exocytosis of the biosilica building blocks is a striking example of polarized intracellular membrane trafficking [6]. Several components involved in silica formation have previously been identified (see below), but the molecular machineries for SDV biogenesis and exocytosis have so far remained unknown [6-8]. The SDVs are closely associated with the actin filaments and microtubules which likely play a role in positioning and shaping of the SDVs [1, 7, 9-11]. It has been suggested that the cytoskeleton may guide morphogenesis of the 
porous silica nanopatterns through interactions with proteins that span the SDV membrane. Such membrane proteins would carry cytoskeleton binding domains on the cytosolic side and mineral interaction domains on the part of the protein that is exposed to the lumen of the SDV [12]. To date, there are no published reports on SDV membrane proteins from diatoms or any other silica forming organisms. In fact, hardly any information is available about the membrane proteins of eukaryotic biomineralization vesicles due to the lack of methods for isolating these subcellular compartments.

Previous biochemical analysis has led to the identification of unique proteins (silaffins, cingulins, silacidins) and long-chain polyamines (LCPA) as organic components of diatom biosilica. Most of the biosilicaassociated proteins are highly charged and hydrophilic, predicted to be intrinsically disordered, and some of them have been shown to highly accelerate silica formation from monosilicic acid solutions in vitro [13-17]. A recent proteomics analysis revealed several novel biosilica-associated proteins with unknown functions in the diatom Thalassiosira pseudonana [17]. One of these, SiMat7, differs markedly from silaffins, cingulins, and silacidins regarding amino acid composition and predicted secondary structure. In the present work, we have investigated the function of SiMat7 by (1) determining its intracellular locations at different stages of the cell cycle, (2) probing its association with cellular membranes and with biosilica, and (3) analyzing its selfassembly properties and silica formation activity. Here, we demonstrate that SiMat7 is the founding member of a novel family of silica biomineralization proteins, which we named silicanins. Accordingly, SiMat7 was re-named silicanin-1 (abbreviated Sin1).

\section{Results}

Molecular architecture and sequence conservation of $\operatorname{Sin} 1$ Sin 1 is comprised of 426 amino acids and is a predicted type 1 transmembrane protein with a 20 amino acid cytosolic domain at the $\mathrm{C}$-terminus preceded by a single transmembrane helix of 20 amino acids (Fig. 1). The cytosolic domain does not contain known cytoskeleton binding sites or any other known motifs. The remaining part of Sin1 is predicted to be exposed to the extracellular space or the lumen of a secretory compartment due to the presence of an $\mathrm{N}$-terminal signal peptide for cotranslational import into the endoplasmic reticulum (Fig. 1). The signal peptide is followed by a stretch of 30 amino acids ending with the tripeptide RRL, which is typical for many diatom biosilica-associated proteins and is denoted the RXL domain (Fig. 1) [14-17]. The majority of Sin 1 is composed of a 341 amino acid polypeptide region rich in asparagine and glutamine, which are often present in clusters (NQ-rich domain). The NQ-rich domain of Sin 1 also contains 18 cysteine residues, and secondary structure analysis predicts it to be folded with $28 \% \alpha$ helix, $14 \% \beta$ sheet, and $58 \%$ disordered regions. This suggests that the 3D structure of Sin 1 is very different from those of silaffins, cingulins, and silacidins, which contain only one or no cysteine residues and are

a

1 MKFVLPAILLATATANPFAPKOTRNTKKAAYAASIMRGATPLRRUEDAYD

51 GQVDVDLSGYSVKFEKCQFVKQYEGGEGGNLNNKNGNGEQFLSTKRFVIF

101 RLCPDSSCSSCNYNYGEYIVDMDTYLESTLQYKOEEQETYCQSCQQCVEM

151 QANANNGDANDDQNLDNAWMCNNIDTSTCYDECQNIENMEANGYMDASEL

201 TGCVKMNYQDNYGNAYYAGAMCASSGTRIKIGVFSDEQCSQVVEDADIET

251 YLAYGNNNDNNNGVTMKLSYHLLKQTFPESGCVSSCLKONFNONNNNNNN

301 GEQQAAEVNEICENLYEVAGKCESTHGFKTGYANYDNYENQIRNEELVCD

351 FISSVSAGHYDQTGEIVVSGGRTTLGGGVATTGGQKFALTFFILGSVGLA

401 GYAAMLHQQLTKGAKADLSRQGGAMA

b

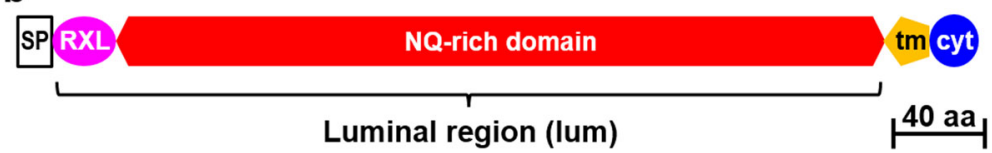

Fig. 1 Sequence analysis of Sin1. a Analysis of the amino acid sequence of Sin1. The signal peptide is depicted in italics and underlined, the RXL domain is highlighted in purple, and clusters that are rich in $\mathrm{N}$ and $\mathrm{Q}$ are presented on a red background. The transmembrane helix is highlighted in orange and the cytosolic domain in blue. The N-terminal signal peptide and the transmembrane helix were identified using the SignalP v.4.1 [47] and TMHMM V.2 [48] webservers, respectively. $\mathbf{b}$ Schematic of the domain arrangement in Sin1. SP signal peptide, RXL RXL domain, tm transmembrane helix, cyt cytosolic domain 
predicted to adopt entirely random coil structures. Sin1 does not exhibit significant sequence similarity to any other previously described silica-associated proteins. The genome of $T$. pseudonana encodes a protein with $55 \%$ sequence identity to $\operatorname{Sin} 1$, which we coined $\operatorname{Sin} 2$ (Additional file 1: Figure S1).

A search in the NCBI database retrieved homologous proteins exclusively from diatoms (note, only proteins with an E-value lower than $1 \times 10^{-50}$ were considered as homologs). We then extended our search for Sin1 homologs by performing a Basic Local Alignment Search Tool (BLAST) search in the Microbial Eukaryote Transcriptome Sequencing Project (MMETSP) database, which contains a large amount of gene sequences of eukaryotic microbes that are absent from the NCBI database [18]. This retrieved Sin 1 homologs from 70 diatom species and from two non-diatom organisms (Additional file 1: Table S1). The three closest Sin1 homologs from centric diatoms have a higher sequence identity to $\operatorname{Sin} 1(66 \%)$ than the three closest homologs from pennate diatoms (46-47\%) (Additional file 1: Table S2). The two non-diatom organisms harboring Sin1 homologs are the amoeboid alga Rhizochromulina marina (62\% amino acid sequence identity) and the colepid ciliate Tiarina fusa (49\% sequence identity). Sin1 homologs appeared to be absent from other unicellular silicaforming organisms in the MMETSP database such as synurophyceae (four species in the MMETSP database), chrysophyceae (six species), dictyochophyceae except for Rhizochromulina marina (eight species), and loricate choanoflagellates (one species). Unfortunately, genome or transcriptome data from other biosilica-forming organisms such as actinophryids, radiolarians and the silicaforming coccolithophore Prymnesium neolepis [19] were not publicly available. Furthermore, Sin 1 homologs could not be found in the genome of the siliceous sponge demosponge Amphimedon queenslandica [20].

All Sin1 homologues identified here are also predicted type 1 transmembrane proteins, share the same domain composition and arrangement, and the positions of the 18 cysteine residues in their NQ domains are conserved (Additional file 1: Figure S1). Therefore, we regard these proteins as members of the silicanin protein family, and assume that they exhibit 3D structures and biological functions that are very similar to Sin1.

\section{Membrane association of Sin 1}

To examine whether Sin 1 is membrane-associated as predicted (see above), we isolated total membranes from T. pseudonana according to an established protocol [21]. Using Western blot analysis, the membranes were probed for the presence of Sin1 with an antibody directed against the luminal region of $\operatorname{Sin} 1$ (i.e., the combined RXL and NQ domains; Fig. 1b). A single intense band of $55 \mathrm{kDa}$ apparent molecular mass was detected, which is about $10 \mathrm{kDa}$ higher than was expected for a Sin1 molecule lacking the signal peptide (predicted molecular mass: $45.2 \mathrm{kDa}$; Fig. 2a). To investigate whether the difference in apparent molecular mass was caused by an unusual migration behavior of Sin1 on sodium dodecyl sulfate (SDS)-polyacrylamide gel electrophoresis (PAGE), we expressed two recombinant Sin1 proteins in E. coli. Protein $\mathrm{rSin}^{\mathrm{SP}}$ (molecular mass: $45.1 \mathrm{kDa}$, Additional file 1: Figure S2a) contained all Sin1 domains except the signal peptide, and protein rSin1 $1^{\text {lum }}$ (molecular mass: $40.7 \mathrm{kDa}$ ) was only composed of the luminal region (Additional file 1: Figure S2b). On SDS-PAGE, both proteins also had apparent molecular masses around $55 \mathrm{kDa}$, demonstrating that Sin1 indeed exerts an aberrant migration behavior on SDS-PAGE (Fig. 2a). Therefore, we concluded that the $55 \mathrm{kDa}$ band in the membrane fraction of T. pseudonana corresponds to Sin1. Its apparent molecular mass is slightly higher than $\mathrm{rSin} 1^{\mathrm{lum}}$, which would be consistent with the presence of the transmembrane helix and cytosolic domain in Sin1 provided that this protein does not contain significant amounts of post-translational modifications. After treatment of $T$. pseudonana membranes with anhydrous HF, which removes O-linked glycans and Ophosphoryl moieties [22], the apparent molecular mass of Sin1 remained unchanged (Fig. 2b). This indicates the absence of substantial amounts of glycan and phosphate moieties in native $\operatorname{Sin} 1$. The fact that the apparent

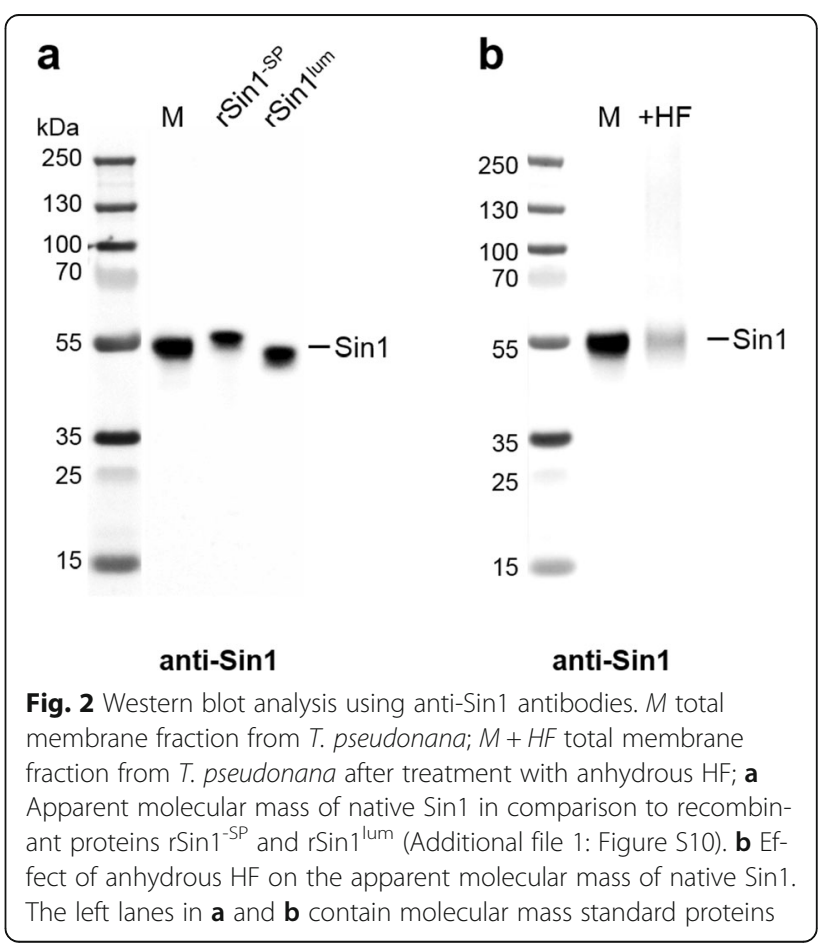


molecular mass of Sin 1 is is slightly lower than $\mathrm{rSin}^{1}{ }^{\mathrm{SP}}$ (Fig. 2a) suggests that Sin1 may lack the RXL domain. Proteolytic removal of RXL domains by a yet unknown protease has been observed in other biosilica-associated proteins such as silaffins [13].

To test whether the predicted transmembrane domain of Sin1 is integrated into the lipid bilayer, isolated total membranes of $T$. pseudonana were extracted with a carbonate containing buffer at $\mathrm{pH}$ 11.5. Under these conditions, proteins containing a domain that fully penetrates the lipid bilayer remain bound to the membrane, whereas proteins that are peripherally associated with the membrane become completely solubilized [23]. Western blot analysis revealed that approximately half of the Sin 1 molecules remained associated with the carbonate extracted membranes (Additional file 1: Figure S3a, Additional file 1: Table S3). Under the same conditions, the peripheral membrane protein AtpB ( $\beta$-subunit of plastidic/mitochondrial ATP synthase) was completely extracted from the membranes, and the integral membrane protein PsbD (5 transmembrane helices) remained entirely in the membrane (Additional file 1: Figure S3b, c, and Table S3). Regarding the partial extractability from membranes using alkaline carbonate buffer, Sin1 is similar to other type 1 transmembrane proteins, for example, like the $\beta$ subunit of the SRP receptor [24] and the lysosomal transmembrane protein NCU-G1 [25]. Therefore, the fact that approximately half of the Sin1 protein molecules remain associated with the membrane rather than becoming fully extracted by alkaline carbonate buffer is regarded as a proof for transmembrane anchoring of Sin1.

\section{Localization and silica embedment of $\operatorname{Sin} 1$}

To investigate the intracellular location and silica association of Sin1, two GFP fusion proteins, Sin1-GFP ${ }^{\mathrm{N}}$ and Sin1-GFP ${ }^{C}$, were independently expressed in T. pseudonana. In Sin1-GFP ${ }^{\mathrm{N}}$ the GFP is located right between the RXL domain and the NQ-rich domain (i.e., in the predicted extracellular/luminal region of Sin1). In Sin1$\mathrm{GFP}^{\mathrm{C}}$, the GFP-tag is attached to the end of the predicted cytosolic domain. Fluorescence microscopy analysis of transformant cells expressing Sin1-GFP ${ }^{\mathrm{N}}$ revealed GFP fluorescence in the valve and girdle band regions of live cells and in isolated biosilica (Fig. 3a, b top panel). After complete removal of the silica, the GFP was present in ring-shaped, purely organic structures (Fig. 3b top panel ). This confirmed that Sin1 is a component of the previously described biosilica-associated insoluble organic matrices $[16,17]$ from which it has recently been identified by proteomics analysis [17]. Accessibility experiments using anti-Sin1 antibodies, which were directed against the luminal domain of $\operatorname{Sin} 1$ (amino acids $25-383$ ), demonstrated that less than $20 \%$ of the $\operatorname{Sin} 1$ molecules were accessible in biosilica isolated from Sin1$\mathrm{GFP}^{\mathrm{N}}$ expressing cells compared to their accessibility in the silica-free insoluble organic matrices (Additional file 1: Figure S4, Additional file 1: Table S4). This result indicated that the Sin 1 molecules are largely embedded inside the biosilica, which implies that they are exposed to the lumen of the SDVs during silica deposition in vivo.

In cells expressing Sin1-GFP ${ }^{C}$, GFP-fluorescent ringlike structures and plate-like structures appeared transiently during girdle band and valve morphogenesis, respectively (Fig. 3a, b, bottom panel). Strong GFP fluorescence was also associated with intracellular spherical structures that were moving throughout the cytoplasm, whereas GFP fluorescence appeared to be absent from the biosilica cell walls (Fig. 3b bottom panel, Additional file 2: Movie S1). Indeed, biosilica and organic matrices prepared from cells expressing Sin1-GFPC did not exhibit any GFP fluorescence (Fig. 3b, bottom panel). This seemed to indicate that $\operatorname{Sin} 1$ is absent from the biosilica and the organic matrices, which would contradict the result obtained with cells expressing Sin1-GFP ${ }^{\mathrm{N}}$. To resolve this discrepancy, T. pseudonana transformants were generated to express the fusion protein Sin1$\mathrm{mT}^{\mathrm{N}}{ }^{\mathrm{N}}$-Venus ${ }^{\mathrm{C}}$. In this fusion protein the cyan fluorescing protein mTurquoise 2 (mT2) was positioned within the luminal region (between the RXL domain and NQ domain) and the yellow fluorescing protein Venus was attached to the C-terminus. Live transformant cells exhibited both cyan fluorescence and yellow fluorescence (Additional file 1: Figure S5a), confirming that the full length double fluorescent-tagged Sin1 protein molecules were expressed. The cyan fluorescence was present in the biosilica of live cells (Additional file 1: Figure S5a), in isolated biosilica, and in the insoluble organic matrices (Additional file 1: Figure S5b). In contrast, the yellow fluorescence was absent from the biosilica and the insoluble organic matrices (Additional file 1: Figure S5a, b). This result can be explained by assuming a proteolytic cleavage between the luminal region and the C-terminal part of Sin1 during silica biogenesis. Only the luminal domain of Sin1 rather than the transmembrane helix and cytosolic domain would become incorporated into the biosilica (Fig. 3c). This scenario is also consistent with the presence and absence of GFP fluorescence in biosilica from transformants expressing $\operatorname{Sin} 1-\mathrm{GFP}^{\mathrm{N}}$ and Sin1$\mathrm{GFP}^{\mathrm{C}}$, respectively (see Fig. $3 \mathrm{~b}$ ). The heptapeptide motif GGQKFAL, which is right at the transition of the luminal region to the transmembrane domain, is perfectly conserved in all silicanin sequences (see Additional file 1: Figure S1) and might be the recognition site for a silicaninspecific protease. To exclude the possibility that the lack of GFP fluorescence in biosilica from Sin1-GFP ${ }^{C}$ transformants was due to denaturation of GFP, immunolabeling experiments were performed using a polyclonal anti-GFP 


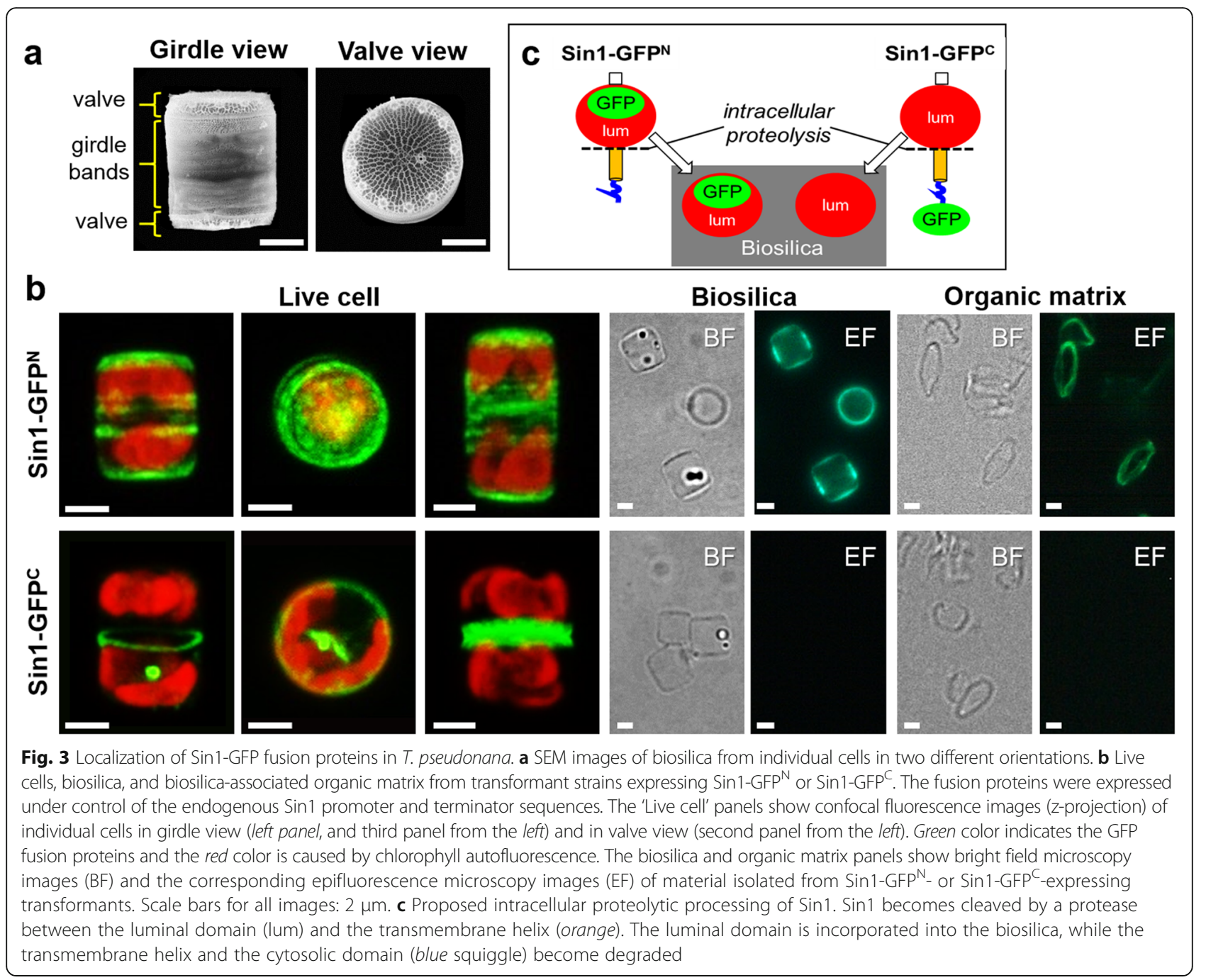

primary antibody and an AlexaFluor647 (AF) conjugated secondary antibody. The GFP fluorescent biosilica and organic matrices from Sin1-GFP ${ }^{\mathrm{N}}$ expressing cells also exhibited AF fluorescence, demonstrating accessibility of biosilica and organic matrix bound GFP molecules for the anti-GFP antibodies (Additional file 1: Figure S6). No AF fluorescence was detected in the biosilica and the organic matrices from Sin1-GFPC ${ }^{C}$ cells (Additional file 1: Figure S6), thereby confirming the absence of GFP, which is in agreement with C-terminal proteolytic processing of Sin 1 upon incorporation into the biosilica (Fig. 3).

\section{Time-lapse imaging of Sin1-GFP ${ }^{C}$}

To investigate the location of Sin1 during the cell cycle, time lapse confocal fluorescence microscopy with individual cells expressing Sin1-GFP ${ }^{C}$ was performed. Biosilica produced during imaging was labeled by pre-loading the cells with the dye 2-(4-pyridyl)-5-((4-(2-dimethylaminoethylaminocarbamoyl)methoxy)phenyl)oxazole (PDMPO). PDMPO is known to accumulate in silica deposition vesicles and remains permanently entrapped inside the biosilica also after exocytosis, but it does not stain mature biosilica that is already present on the cell surface [26]. Inside Sin1-GFP ${ }^{C}$ expressing cells, several GFP-fluorescent spherical particles were present. The particles were quite mobile but most of the time remained close to the region where the cleavage furrow will appear (i.e., the mid-cell region), and seem to be associated with weakly GFP fluorescent mobile strands (Additional file 2: Movie S1). During the entire cell cycle, GFP fluorescence is also present throughout the plasma membrane (Additional file 2: Movie S1). In Fig. 4, still images from Additional file 2: Movie S1 from the GFP channel (Sin1-GFPC localization; Fig. 4b), from the PDMPO channel (biosilica localization; Fig. 4c), and the corresponding merged images from the two channels (Fig. 4d) are shown. Additionally, schematic drawings are presented showing the characteristic stages of the cell cycle (Fig. 4a). We assume that biogenesis of valve biosilica is complete when GFP and PDMPO fluorescence in the mid-cell region reach their maximum intensity. This time point was defined as 


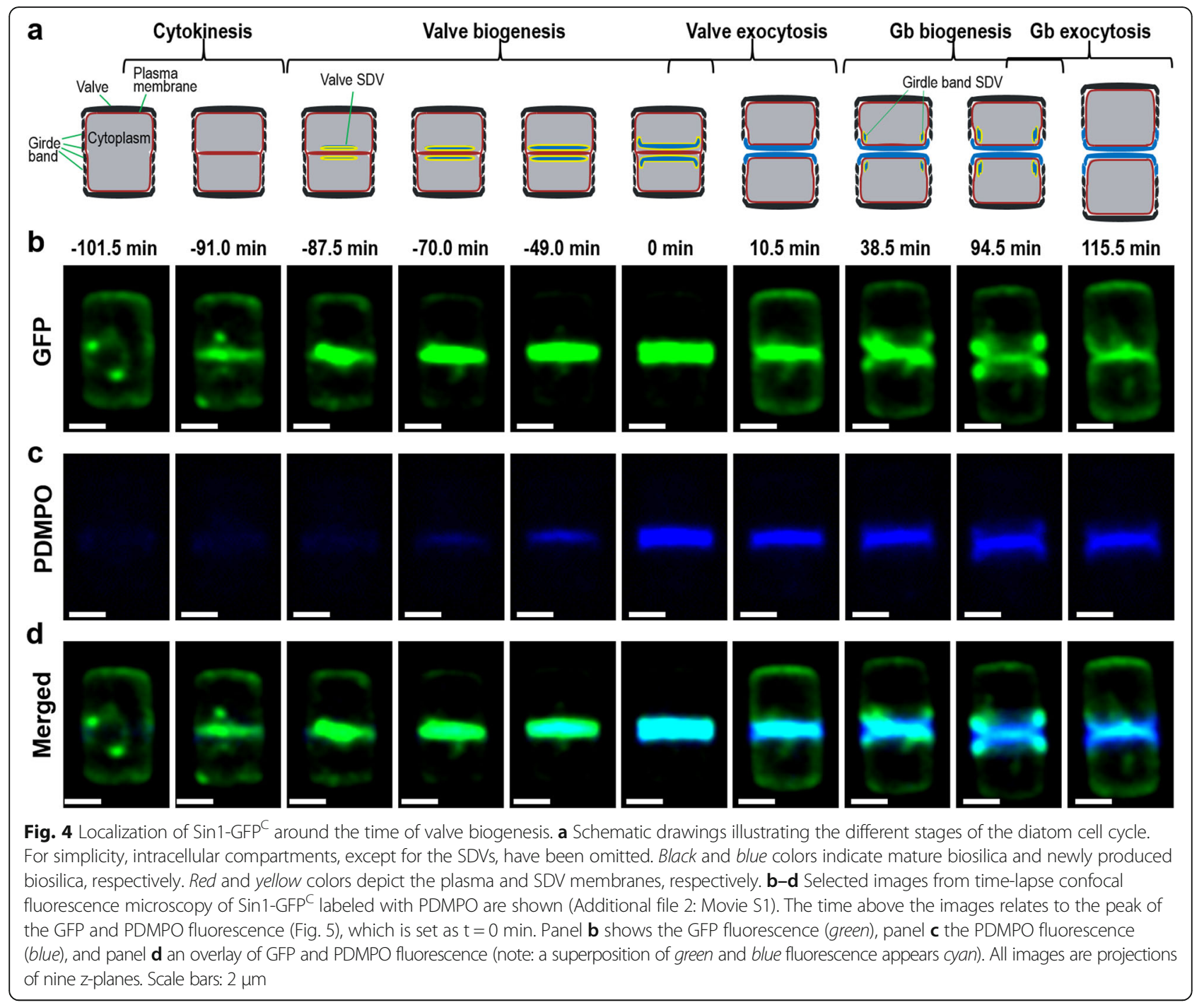

$\mathrm{t}=0 \mathrm{~min}$ (approximately in the middle of Additional file 2: Movie S1). Therefore, all events preceding the completion of valve biogenesis are assigned negative times.

At $\mathrm{t}=-101.5 \mathrm{~min}$ the cell was in late interphase, and GFP fluorescence was present throughout the cell periphery (i.e., the region of the plasma membrane) as well as in spherical particles and associated strands inside the cell (Fig. 4b, $\mathrm{t}=-101.5 \mathrm{~min}$ ). Nuclear division typically was completed by $\mathrm{t}=-95.0 \mathrm{~min}$ (Additional file 3 : Movie S2, Additional file 1: Figure S7), and shortly thereafter GFP fluorescence was present throughout the mid-cell region (Fig. $4 \mathrm{~b}, \mathrm{t}=-91.0 \mathrm{~min}$ ). We assume that, at this time point, cytokinesis has just been completed and thus the GFP-fluorescent plasma membranes of the two sibling cells are adjacent to one another in the mid-cell region. Shortly after cytokinesis, GFP fluorescence strongly increased in the mid-cell region starting from the center (Fig. $4 \mathrm{~b}, \mathrm{t}=-87.5 \mathrm{~min}$ ) and expanding until it spanned the entire middle plane (Fig. $4 \mathrm{~b}, \mathrm{t}=-49.0 \mathrm{~min}$ ). Fluorescence in the mid-cell region appeared to steadily increase until the end of valve biogenesis (Fig. 4b, t=0 min). Less than $20 \mathrm{~min}$ after the onset of strong GFP fluorescence in the mid-cell region and in co-localization, PDMPO fluorescence appeared and continuously increased (Fig. 4b, c, -70.0 to $0 \mathrm{~min}$ ). These observations demonstrated (1) the development of a valve biosilica in each sibling cell during the time period from -70 to $0 \mathrm{~min}$, and (2) the colocalization of Sin 1 with the valve SDVs during silica biogenesis. During the following 10 minutes, GFP fluorescence intensity in the mid-cell region decreased drastically while GFP fluorescence in the entire plasma membrane region of each sibling cell increased (Fig. 4b, $\mathrm{t}=0$ to $10.5 \mathrm{~min}$ ). This was confirmed by quantitative analysis of the fluorescence intensity, which revealed identical fast kinetics for the GFP loss in the mid-cell 
region and the increase of GFP fluorescence in the plasma membrane region upon exocytosis of the valves from the two sibling cells (Figs. 4b and 5a). Consistent with this assumption was the simultaneous sudden drop in fluorescence intensity of the biosilicabound PDMPO (Figs. 4c and 5b). Upon exocytosis, the $\mathrm{pH}$ in the vicinity of the biosilica changes from acidic inside the SDVs [27] to near neutral on the cell surface. In this $\mathrm{pH}$ range, PDMPO fluorescence intensity in the recorded wavelength range $(510-540 \mathrm{~nm}$ ) decreases with increasing $\mathrm{pH}[26,28]$. Furthermore, it is possible that PDMPO molecules, which had accumulated inside the SDVs but were not entrapped inside the newly produced biosilica, rapidly diffused into the surrounding medium upon exocytosis.

Shortly after exocytosis of the valves, the distance between the centers of the two sibling cells had increased and several spherical GFP-fluorescent particles and associated GFP-fluorescent strands reappeared in the sibling cells near their contact region (Fig. $4 \mathrm{~b}, \mathrm{t}=38.5 \mathrm{~min}$ ). We assume that the GFP-fluorescent spherical particles and associated strands, which were also observed before the onset of valve biogenesis (Fig. $4 \mathrm{~b}, \mathrm{t}=-101.5 \mathrm{~min}$ ), are membrane-bounded compartments that Sin1 passes through on its way to the SDV. During valve biogenesis these structures appeared to have fused with the developing valve SDVs in the mid-cell region. Between 38.5 and $101.5 \mathrm{~min}$, in each sibling cell, a GFP-labeled, ringshaped structure was present and located near the edges of the newly produced valves (Fig. $4 \mathrm{~b}, \mathrm{t}=94.5 \mathrm{~min}$ ). In this location the first girdle band SDV is supposed to develop in each sibling cell. Indeed, silica biogenesis was confirmed by the co-localization of GFP with PDMPO fluorescence (Fig. 4b, c, t=94.5 min). Like with valve exocytosis, GFP fluorescence intensity at the sites of girdle band formation rapidly decreased during exocytosis while GFP fluorescence in the entire plasma membrane simultaneously increased with the exocytosis of each girdle band (Fig. 4a, $\mathrm{t}=115.5 \mathrm{~min}$; Additional file 4: Movie S3; Additional file 1: Figure S8, $\mathrm{t}=101.5$ to $112 \mathrm{~min})$.

The results from the imaging of Sin1-GFP ${ }^{C}$ during the cell cycle are consistent with Sin1 being anchored in the SDV membrane during silica biogenesis. We regard the strong increase of Sin1-GFP ${ }^{C}$ fluorescence in the mid-cell region at $t=-87.5 \mathrm{~min}$ as the onset of valve SDV development (Fig. 4b). By $t=-70$ min, Sin1$\mathrm{GFP}^{\mathrm{C}}$ had fully extended across the entire mid-cell region (Fig. 4b), and only at this time point did silica deposition become noticeable (Fig. 4c). This result indicates that the development of the valve SDVs precedes the deposition of silica, which is in agreement with the results from a previous ion-abrasion electron microscopy study on T. pseudonana [29].

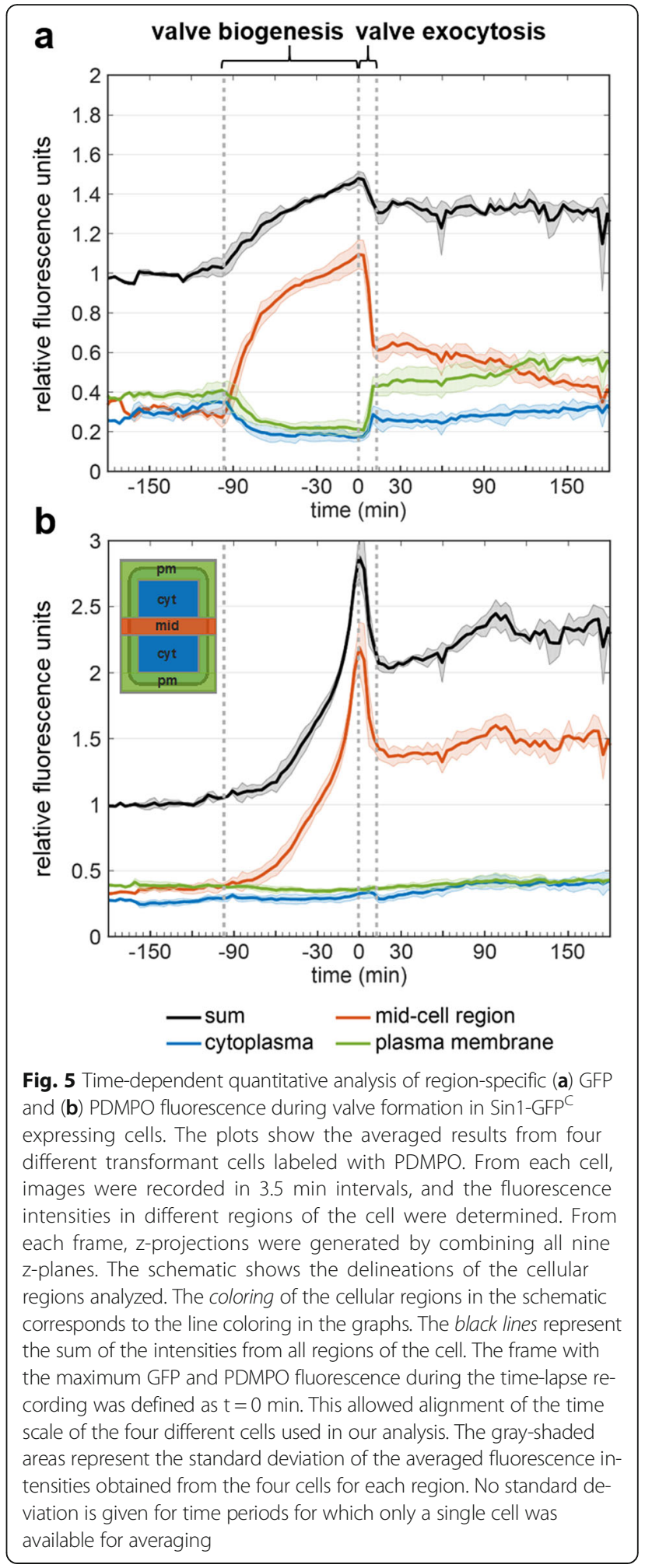

The sudden decrease of GFP fluorescence in the midcell region of the cell and the simultaneous increase in GFP fluorescence in the plasma membrane during exocytosis of the valve (Fig. $5 \mathrm{a}, \mathrm{t}=0$ to $10.5 \mathrm{~min}$ ) and girdle 
band biosilica (Additional file 1: Figure S8, $\mathrm{t}=100$ to $115 \mathrm{~min}$ ) can be explained by fusion of the SDV membranes with the plasma membrane. This enabled the SDV-derived Sin1-GFP ${ }^{C}$ molecules to diffuse across the entire plasma membrane, thus substantially decreasing in abundance at the site of biosilica exocytosis. However, the decrease of GFP fluorescence in the mid-cell region during valve exocytosis was only partially compensated by the increase of GFP fluorescence in the plasma membrane. During this time, GFP fluorescence in the cytoplasm increased only moderately (blue trace in Fig. 5a, $\mathrm{t}$ $=0$ to $10.5 \mathrm{~min}$ ), and thus the sum of cellular GFP fluorescence decreased (black trace in Fig. $5 \mathrm{a}, \mathrm{t}=0$ to $10.5 \mathrm{~min})$. As GFP fluorescence outside the cell did not increase, the result suggests that a fraction of the Sin1$\mathrm{GFP}^{\mathrm{C}}$ molecules was proteolytically degraded during valve exocytosis. From the normalized GFP fluorescence data (Fig. 5a) it was estimated that the total amount of Sin1-GFP ${ }^{C}$ molecules increased by approximately $50 \%$ during valve biogenesis $(t=-87.5$ to $0 \mathrm{~min})$. The subsequent drop in total GFP fluorescence indicated that roughly one-third of the newly synthesized $\operatorname{Sin} 1-$ GFP $^{\mathrm{C}}$ molecules were degraded during valve exocytosis $(t=0$ to $10 \mathrm{~min}$ ). This degradation-prone fraction may be formed by Sin1-GFP ${ }^{C}$ molecules from which the luminal region was proteolytically cleaved off and incorporated into the biosilica. The remaining GFP-tagged C-terminal part (containing the transmembrane and cytosolic domains of Sin1) may have then become rapidly degraded, thus eliminating the GFP fluorescence. In contrast, Sin1$\mathrm{GFP}^{\mathrm{C}}$ molecules that retain the luminal region during silica biogenesis may be resistant to such fast proteolysis, and after valve exocytosis would become components of the plasma membrane.

\section{Properties of recombinant $\operatorname{Sin} 1^{\text {lum }}$}

To further investigate the function of Sin 1 in silica biogenesis, we studied the properties of the recombinantly expressed luminal region of $\operatorname{Sin} 1$ ( $\mathrm{rSin} 1^{\mathrm{lum}}$, aa 25-383), which contains most of the RXL domain, the NQ domain, and a C-terminal hexahistidine tag (Additional file 1: Figures S2b, S9a). This recombinant protein comprises $84 \%$ of the Sin 1 polypeptide sequence and is expected to be present at the luminal side of the SDV membrane (see above), which is a key interface in silica morphogenesis [12]. Analysis by circular dichroism spectroscopy indicated that $\mathrm{rSin} 1^{\text {lum }}$ is a globular protein with a combined $\alpha$ helix and $\beta$ sheet content of 40\% (Additional file 1: Figure S8b, Additional file 1: Table S5). Using Ellman's reagent, it was demonstrated that all 18 cysteine residues in $\mathrm{rSin} 1^{\text {lum }}$ are engaged in disulfide bonds (Additional file 1: Table S6). Dynamic light scattering (DLS) revealed that $\mathrm{rSin} 1^{\text {lum }}$ has a hydrodynamic diameter of $6.8 \pm 0.6 \mathrm{~nm}$ at $\mathrm{pH} 7.7$
(Fig. 6), which closely matches the theoretical prediction of $6.6 \mathrm{~nm}$ for a monomeric, globular protein with 428 amino acids (i.e., the number of amino acids in rSin $1^{\text {lum }}$ ) [30]. Although the solution was almost exclusively composed of monomers ( $>99 \%$ by mass) at $\mathrm{pH}$ 7.7, a small amount of $\mathrm{rSin} 1^{\text {lum }}$ clusters with a hydrodynamic diameter $\left(D_{h}\right)$ of $156 \pm 36 \mathrm{~nm}$ was detected (see dotted line for $\mathrm{pH} 7.7$ in Fig. 6). When the solution was acidified to $\mathrm{pH} 5.5$, larger amounts of rSin $1^{\text {lum }}$ clusters with $D_{h}=54 \pm 12 \mathrm{~nm}$ were detected, yet the solution was still mainly composed of monomers ( $~ 99 \%$ by mass; Fig. 6). A further moderate increase of acidity to $\mathrm{pH} 5.2$ and $\mathrm{pH} 5.0$ induced quantitative formation of $\mathrm{rSin} 1^{\text {lum }}$ clusters with $\mathrm{D}_{\mathrm{h}}=$ $108 \pm 36 \mathrm{~nm}$ and $\mathrm{D}_{\mathrm{h}}=1806 \pm 316 \mathrm{~nm}$, respectively (Fig. 6). After decreasing the acidity by adjusting the $\mathrm{pH}$ to 6.5 , the clusters disassembled within 1 hour, yielding almost completely monomeric $\mathrm{rSin} 1^{\mathrm{lum}}(\sim 98 \%$ by volume; Fig. 6). This result indicated that $\mathrm{pH}$ induced assembly of $\mathrm{rSin} 1^{\text {lum }}$ clusters is a reversible process. Cryo-electron microscopy revealed that the rSin $1^{\text {lum }}$ clusters had spherical shapes with a relatively wide size distribution that increased with decreasing $\mathrm{pH}$, and was within the size range determined by DLS (Fig. 7a). Growth of the clusters appeared to occur through fusion (Fig. 7b), but we cannot exclude the possibility that addition of $\mathrm{rSin} 1^{\text {lum }}$ monomers also contributed to cluster growth. We assume that the $\mathrm{pH}$ triggered, reversible formation of aggregates is a physiologically relevant property of Sin1, because diatom SDVs are acidic compartments [27].

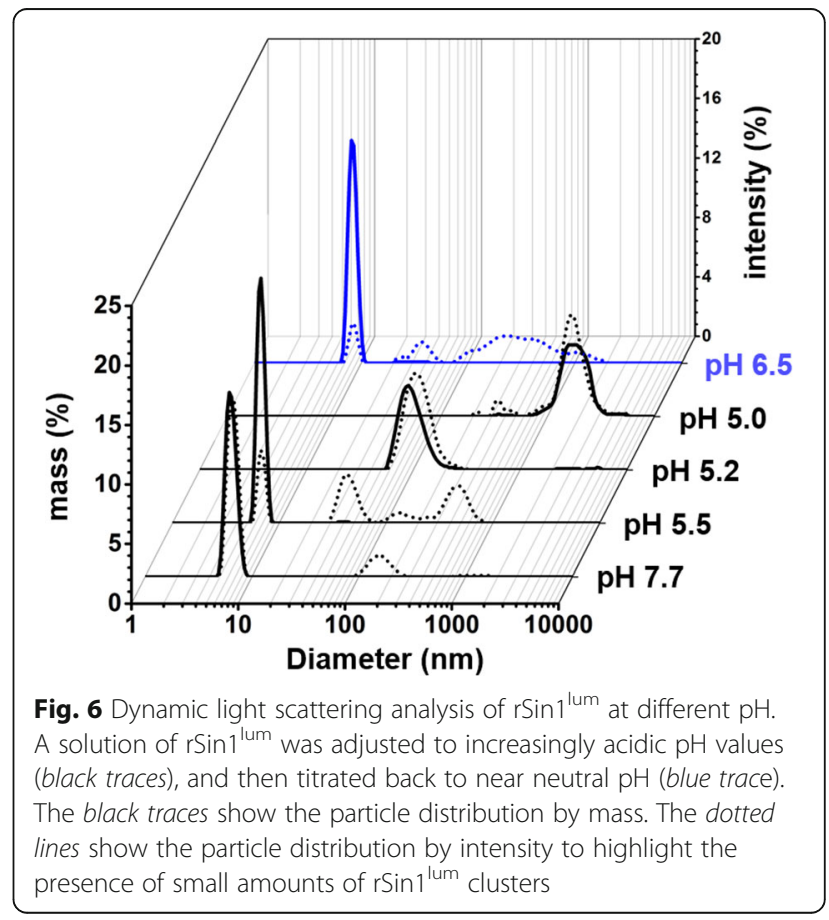


a
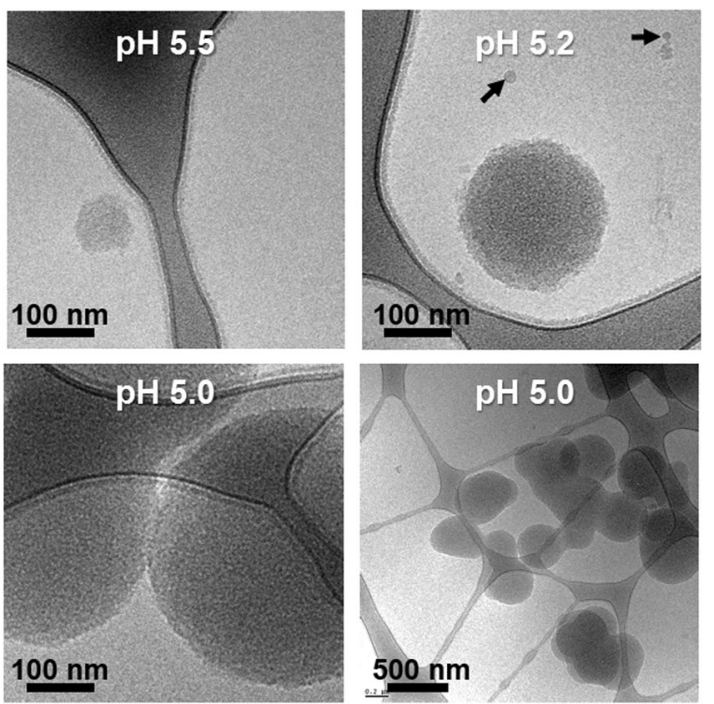

b
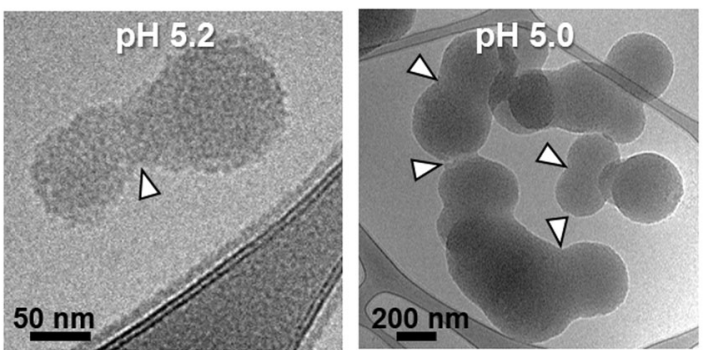

Fig. 7 Cryo-electron microscopy analysis of r $\operatorname{Sin} 1^{\text {lum }}$ clusters. a Clusters at different $\mathrm{pH}$ values 60 min after adjustment to the indicated $\mathrm{pH}$. The black arrows point to small clusters that consist of only 10-20 protein monomers. b Clusters at pH 5.2 (left) and pH 5.0 (right). The arrowheads point to neck regions between two clusters that are indicative of fusion events

As the luminal domain of Sin1 is embedded inside the silica (Additional file 1: Table S4), we investigated whether this part may be directly involved in the deposition of silica inside the SDVs. Therefore, we analyzed the silica formation activity of $\mathrm{rSin} 1^{\mathrm{lum}}$ in vitro at $\mathrm{pH}$ 5.5, which is presumed to be close to the physiological $\mathrm{pH}$ inside the SDVs [27, 31, 32]. Only small amounts of silica $\left(20 \pm 2 \mathrm{nmol} \mathrm{SiO}_{2}\right)$ were formed when rSin1 $1^{\text {lum }}$ was incubated with monosilicic acid. Previously, it has been shown that strongly negatively charged diatom phosphoproteins (e.g., silaffins tpSil3, tpSil1/2H, silacidins) do not have silica-formation activities by themselves, yet mixtures of the phosphoproteins with LCPA or mixtures of polyamines with phosphate exhibited high silica formation activity $[14,15,33]$. The luminal region of $\operatorname{Sin} 1$ is predicted to be highly negatively charged at $\mathrm{pH} 5.5$ due to the presence of many aspartate and glutamate residues ( $14 \%$ of the total amino acids; predicted isoelectric point is 4.5). Therefore, we investigated the silica formation activity of $\mathrm{rSin} 1^{\text {lum }}$ in the presence of LCPA. An equimolar mixture of $\mathrm{rSin} 1^{\text {lum }}$ with
LCPA (25 $\mu \mathrm{M}$ each) produced $104 \pm 1 \mathrm{nmol} \mathrm{SiO}_{2}$, which was more than five- and seven-fold higher than that of rSin $1^{\text {lum }}$ (see above) and LCPA $(15 \pm 5 \mathrm{nmol})$ by themselves. The silica formation activity of the $\mathrm{rSin} 1^{\text {lum }}$-LCPA mixture had more than double the activity of an LCPAphosphate mixture $\left(50 \pm 6 \mathrm{nmol} \mathrm{SiO}_{2}\right)$. These data demonstrated that $\mathrm{rSin} 1^{\text {lum }}$ interacts with LCPA, resulting in a high silica formation activity at near physiological $\mathrm{pH}$ conditions.

\section{Discussion}

In the present work, we have identified $\operatorname{Sin} 1$ as the first SDV transmembrane protein. Bioinformatics analysis revealed that $\operatorname{Sin} 1$ is highly conserved throughout the diatom realm, and homologous proteins were also identified in two non-diatom organisms. One of them, the amoeboid alga Rhizochromulina marina, is not reported to produce biosilica, yet it belongs to the taxon Dictyochophyceae, which also includes silicoflagellates that form siliceous skeletons [34-36]. The other nondiatom homologue of Sin 1 is present in the colepid ciliate Tiarina fusa, which is a protozoan that forms a shell made of calcium carbonate [37]. This suggests an evolutionary relationship between the mechanisms for the biomineralization of silica and calcium carbonate, which has recently been also demonstrated for three coccolithophore species [19]. These coccolithophore species encode silicic acid transporter-like proteins and the biomineralization of their calcium carbonate scales was perturbed by germanic acid (i.e., an inhibitor of silica metabolism) [19]. The absence of Sin1 genes in other non-diatom organisms that produce biosilica (e.g., synurophyte Mallomonas sp., chrysophyte Paraphysomonas imperforata, silica sponge Amphimedon queenslandica) indicates that $\operatorname{Sin} 1$ is not universally required for biological silica formation.

Given the high degree of sequence similarity among Sin 1 homologues in centric and pennate diatoms, we assume that Sin 1 may have a fundamental role in the biogenesis of diatom biosilica, which will be discussed below. Based on the data presented in this study, we hypothesize that there are two populations of Sin 1 in the cell. The Sin 1 molecules of one population (in the following referred to as $\operatorname{Sin} 1_{\text {cross }}$ ) become covalently crosslinked via their luminal regions to organic components in the SDV lumen (e.g., through isopeptide bonds, glycosidic bonds, or phosphodiester bonds). This event is part of the self-assembly process of organic components in the SDV lumen that results in a silica-forming insoluble organic matrix. Being part of the silica-forming organic matrix, the luminal regions of the $\operatorname{Sin} 1_{\text {cross }}$ population become encapsulated by silica during silica biogenesis in the SDV lumen. In contrast, the molecules of the other Sin1 subpopulation only loosely interact with the 
components of the silica-forming organic matrix and do not become encapsulated by silica. We assume that, during exocytosis, both the cytosolic domain and the transmembrane helix of the $\operatorname{Sin} 1_{\text {cross }}$ molecules are cleaved off and are then rapidly proteolytically degraded, whereas the luminal region becomes an integral component of the extracellular biosilica. The other population of Sin 1 molecules retain their membrane anchors, and can diffuse throughout the plasma membrane-SDV membrane continuum during exocytosis.

The fate of the SDV membrane after biosilica exocytosis has thus far remained a conundrum. Four scenarios have been suggested [7], namely (1) fusion of the proximal SDV membrane with the plasma membrane, and secretion of vesicles consisting of the distal SDV membrane and the plasma membrane in the region of the cleavage furrow; (2) the same scenario as in (1), but instead of secretion of membrane vesicles the membrane material becomes an organic coat around the distal surface of the biosilica; (3) the entire SDV membrane and the plasma membrane of the cleavage furrow region become an organic coat around the entire biosilica; (4) the proximal SDV membrane fuses with the plasma membrane, whereas the distal SDV membrane is retrieved into the cytoplasm as endocytic vesicles. Previously, no experimental evidence has been provided for any of these scenarios. Our data from quantitative analysis of Sin1-GFP ${ }^{\mathrm{C}}$ localization (Fig. 5a) rule out scenario (1) as we did not observe an increase of GFP fluorescence outside the cells following biosilica exocytosis of valves and girdle bands. Instead, a substantial fraction of the SDV membrane appears to become integrated into the plasma membrane. This can be concluded from the observation that the increase of GFP fluorescence throughout the plasma membrane region during valve exocytosis (from 0.20 relative fluorescence units (RFU) to $0.42 \mathrm{RFU}$ ) accounted for a considerable fraction $(\sim 25 \%)$ of the Sin1-GFP ${ }^{C}$ molecules that had accumulated in the SDV membrane during valve biogenesis (increase of GFP fluorescence from 0.27 RFU to $1.13 \mathrm{RFU}$ ). The observation is consistent with scenarios (2) and (4) and rules out scenario (3), because the latter would require all GFP fluorescence in the mid-cell region to remain associated with the valve biosilica during and after exocytosis, which is not the case (Fig. 5a, red trace at $\mathrm{t}>$ $0 \mathrm{~min}$ ). Only scenario (4) is fully consistent with all our data from quantitative analysis of Sin1-GFP ${ }^{C}$ fluorescence as during valve exocytosis, GFP fluorescence quickly increased in the cytoplasm (from 0.16 to 0.28 RFU) suggesting the retrieval of SDV membrane by endocytic vesicles. Nevertheless, we would like to point out that our conclusions on the fate of the SDV membrane are based on the observation of just a single component of the SDV membrane, Sin1. At this point, it is unclear whether or not $\operatorname{Sin} 1$ is representative of all components of the SDV membrane. Therefore, additional SDV membrane proteins and lipids need to be identified to be able to accurately investigate the fate of the SDV membrane during biosilica exocytosis.

It is reasonable to assume that the function of $\operatorname{Sin} 1$ inside the SDVs will largely depend on the properties of the luminal domain, which represents most of the Sin1 polypeptide. Based on the results from our studies on the recombinant luminal domain, $\mathrm{rSin} 1^{\text {lum }}$, it is likely that the $\operatorname{Sin} 1$ molecules will form clusters on the membrane surface driven by the low $\mathrm{pH}$-induced selfaggregation of the luminal domain (Fig. 6). The shape of the clusters may be isotropic (i.e., circular patches on the membrane surface), which is the natural tendency of the luminal domain (Fig. 7). Alternatively, anisotropically shaped, homomeric or heteromeric clusters may be formed due to the presence of the transmembrane anchor in Sin1, and through interactions with other components in the SDV. It may also be possible that Sin1 covers the entire luminal surface of the SDV membrane, thereby physically separating the luminal space from the membrane. Distinguishing between these three possibilities should be feasible through future experiments localizing Sin 1 by super-resolution fluorescence microscopy in vivo. We hypothesize that the shapes and arrangement of Sin 1 containing clusters on the luminal surface of the SDV membrane is an important determinant for silica morphogenesis. The effect of Sin1 on silica morphogenesis may be exerted via two mechanisms. Firstly, Sin1 clusters may be involved in orchestrating the assembly of the nanopatterned insoluble organic matrix in the SDV lumen. Secondly, through interaction with LCPA molecules, which also bind to silaffins and silacidins $[14,15]$, Sin 1 molecules could mediate the noncovalent binding of aggregates of the soluble components to the surface of the insoluble organic matrix. Aggregates of silaffin-LCPA [14] and silacidin-LCPA [15] have silica forming activities, and thus the distribution pattern of Sin 1 within the insoluble organic matrix would define sites of enhanced silica forming activity. The model could be tested by determining both the distribution pattern of Sin 1 in the isolated organic matrix and the binding sites for LCPA molecules. This could be achieved by immunogold electron microscopy or superresolution fluorescence microscopy using suitable tags for Sin1 and LCPA.

\section{Conclusions}

The present work has provided unprecedented insights into the intracellular locations of a biomineralization protein, Sin1, during silica biogenesis. Sin1 is the first identified SDV membrane protein, and its interaction with LCPA suggests a mechanism by which the SDV 
membrane could influence silica morphogenesis in the SDV lumen. It is to be expected that diatom SDVs contain additional membrane proteins besides silicanins. In 2015, at the meeting "Molecular Life of Diatoms" (in Seattle, WA, USA), a family of putative SDV membrane proteins from $T$. pseudonana were reported by the group of Mark Hildebrand (Scripps Institution of Oceanography, UCSD, USA). These proteins also contain predicted transmembrane domains, but show no sequence similarity to Sin1 (Mark Hildebrand, personal communication). In future work, appropriately tagged Sin 1 could be used as a bait for identification of Sin 1 interacting proteins, and possibly also enable a next big step in silica biomineralization research, namely the isolation of SDVs. Such achievement would allow for in depth characterization of the biomolecular composition of SDVs and studies of their interactions with the cytoskeleton and other cellular components.

\section{Methods}

Chemicals, enzymes, and antibodies

Oligonucleotides were purchased from Eurofins Genomics, isopropylthiogalactoside from Carl Roth, ampicillin from Merck, nourseothricin from Jena Bioscience, tetramethyl orthosilicate (TMOS) from Sigma-Aldrich, and enzymes used for molecular genetics were from obtained Thermo Scientific. Ammonium molybdate tetrahydrate, $\mathrm{NH}_{4} \mathrm{~F}, 37 \%$ $\mathrm{HCl}$, ethylenediamine tetraaecetic acid (EDTA), and sodium dodecylsulfate (SDS) were purchased from Merck. AntirSin $1^{\text {lum }}$ antibodies were produced by Pineda AntibodyService through immunization of rabbits with SDS-PAGE purified $\mathrm{rSin} 1^{\mathrm{lum}}$. A polyclonal anti-GFP antibody (from rabbits) against full-length GFP was obtained from Clontech. Anti-PsbD and anti-AtpB antibodies (both produced in rabbits) were purchased from Agrisera. Anti-rabbit IgG from goat (whole molecule, peroxidase-conjugate) was purchased from Sigma Aldrich. An AlexaFluor647-conjugated anti-rabbit IgG antibody from goat was obtained from Thermo Fisher Scientific. MilliQ-purified $\mathrm{H}_{2} \mathrm{O}$ (resistivity: 18.2 $\mathrm{M} \Omega \cdot \mathrm{cm}$ ) was used throughout this study.

\section{Culture conditions}

Thalassiosira pseudonana (Hustedt) Hasle et Heimdal clone CCMP1335 was grown in an enriched artificial seawater medium (EASW) according to the North East Pacific Culture Collection protocol (Canadian Center for the Culture of Microorganisms ESAW Recipe) at $18{ }^{\circ} \mathrm{C}$ under constant light at 5000-10,000 lux.

Cloning, expression and purification of $r \operatorname{Sin} 1^{\text {lum }}$ and $r \operatorname{Sin} 1^{-S P}$ The DNA sequence of Sin1 is present in the Uniprot database under ID B8CBQ8. The DNA sequences encoding for amino acids $25-383$ of Sin 1 ( $r S i n 1^{\text {lum }}$ ) and amino acids $25-426$ of $\operatorname{Sin} 1\left(\mathrm{rSin} 1^{-\mathrm{SP}}\right)$ were amplified from $T$. pseudonana cDNA, including a hexahistidine coding sequence at the 3 '-ends. The resulting PCR products were incorporated into the expression vector pJ404 (DNA2.0) as described in Additional file 1: Supporting Materials and Methods. Expression and purification of the recombinant proteins from E.coli $\mathrm{DH} 5 \alpha$ is described in detail in Additional file 1: Supporting Materials and Methods.

\section{Isolation of LCPA}

T. pseudonana LCPA were isolated by modification of a previously published method [14]. T. pseudonana biosilica $(\sim 1.2 \mathrm{~g})$ was isolated by SDS/EDTA extraction and incubated with $96 \mathrm{~mL} 10 \mathrm{M} \mathrm{NH}_{4} \mathrm{~F}$ (adjusted to $\mathrm{pH} 4.5$ with $44 \mathrm{~mL} 6 \mathrm{M} \mathrm{HCl}$ ) for $1 \mathrm{~h}$ at room temperature to dissolve the silica. After centrifugation (30 min, $3200 \mathrm{~g}$ ), the supernatant was filtered through a polyethersulfone syringe filter (pore size $0.2 \mu \mathrm{m}$; Carl Roth), and desalted against $200 \mathrm{mM}$ ammonium acetate using a HiPrep 26/10 desalting column (column volume $53 \mathrm{~mL}$, GE Healthcare) injecting $10 \mathrm{~mL}$ of $\mathrm{NH}_{4} \mathrm{~F}$-soluble material per run (flow rate: $9 \mathrm{~mL} \mathrm{~min}{ }^{-1}$ ). Fractions eluting between 1.3 and 3.6 min after sample injection were combined and freeze-dried. The residue was dissolved in $5.5 \mathrm{~mL} \mathrm{H}_{2} \mathrm{O}$, centrifuged (5 min, 20,000 g), and subjected to gel filtration chromatography on a Superose $1210 /$ 300 GL column (GE Healthcare) equilibrated with $200 \mathrm{mM}$ ammonium acetate (flow rate: $0.5 \mathrm{~mL} \mathrm{~min}^{-1}$ ). Fractions eluting between $16.5 \mathrm{~min}$ and $20 \mathrm{~min}$ contained complexes of silaffins and LCPA; they were combined and freeze-dried. The residue was dissolved in $200 \mathrm{mM}$ ammonium acetate supplemented with $2 \mathrm{M}$ $\mathrm{NaCl}$ to disrupt the electrostatic interactions between silaffins and LCPA. After centrifugation (5 min, 20,000 $g$ ), the supernatant was subjected to gel filtration chromatography on a Superdex Peptide 10/300 GL column (GE Healthcare) equilibrated with $200 \mathrm{mM}$ ammonium acetate (flow rate: $0.25 \mathrm{~mL} \mathrm{~min}^{-1}$ ). Fractions eluting between 55 and 61.5 min were combined, freeze-dried, and dissolved in $\mathrm{H}_{2} \mathrm{O}$. Analysis by SDS-PAGE with Coomassie and "Stains All" staining confirmed the purity of LCPA. The concentration of LCPA was determined using the $660 \mathrm{~nm}$ Protein Assay (Pierce) with the synthetic oligopropyleneimine dendrimer DAB-Am-16 (Sigma-Aldrich) as a standard.

\section{Structural and functional characterization of rSin $1^{\text {lum }}$ DLS}

All protein-free solutions were filtered through a polyethersulfone membrane (pore size $0.2 \mu \mathrm{m}$; Carl Roth), and stock solutions of $\mathrm{rSin} 1^{\text {lum }}$ were centrifuged ( $5 \mathrm{~min}$, $20,000 \mathrm{~g})$. The centrifuged $\mathrm{rSin} 1^{\text {lum }}$ stock solution was adjusted to a protein concentration of $1 \mathrm{mg} \mathrm{mL}^{-1}$ by dilution in $10 \mathrm{mM}$ sodium phosphate-citrate at $\mathrm{pH}$ 7.7. 
The solution was incubated at room temperature for 1 hour prior to measurements with a Zetasizer Nano-ZS instrument (Malvern Instruments, UK). The $\mathrm{pH}$ of the rSin $1^{\text {lum }}$ solution was acidified by dropwise addition of $50 \mathrm{mM}$ citric acid, and finally neutralized by dropwise addition of $100 \mathrm{mM} \mathrm{NaOH}$ (note, after all $\mathrm{pH}$ adjustments the increase of sample volume was $<10 \%$ ). After each $\mathrm{pH}$ change, the protein solution was incubated for 1 hour at room temperature, and then measured in a quartz cuvette with $10 \mathrm{~mm}$ path length at $25{ }^{\circ} \mathrm{C}$ using the $173^{\circ}$ Backscatter option of the instrument with automatic determination of the measurement duration. Data processing was performed using the protein analysis model of the Zetasizer software. Data from five measurement runs were averaged.

\section{Cryo-transmission electron microscopy}

All protein-free solutions were filtered through a polyethersulfone membrane $(0.2 \mu \mathrm{m}$ pore size $)$ to remove undissolved particles. The stock solution of $\mathrm{rSin} 1^{\text {lum }}$ ( $4.8 \mathrm{mg} \mathrm{mL}^{-1}$ ) in $10 \mathrm{mM}$ Na-phosphate $\mathrm{pH} 7.7$ was centrifuged ( $5 \mathrm{~min}, 20,000 \mathrm{~g}$ ), diluted to $1.0 \mathrm{mg} \mathrm{mL}^{-1}$ and adjusted to the desired $\mathrm{pH}$ using $50 \mathrm{mM}$ citric acid. Sample vitrification for Cryo-TEM was carried out using an automated vitrification robot (Vitrobot $^{\text {ma }}$ Mark III, FEI). Sample supports (type R2/2 Quantifoil), were purchased from Quantifoil Micro Tools $\mathrm{GmbH}$ and contained a carbon support film on a copper grid. Prior to use, the TEM grids were glow-discharged in a Cressington 208 carbon coater to render them hydrophilic. Cryosamples were prepared from a $3 \mu \mathrm{L}$ droplet of sample solution placed on the grid inside the Vitrobot ${ }^{\mathrm{Tm}}$ chamber at $100 \%$ relative humidity and temperature of $20{ }^{\circ} \mathrm{C}$, after which it was blotted to remove excess solution and subsequently plunged into liquid ethane for vitrification. Imaging was performed using a FEI CryoTitan operating at $300 \mathrm{kV}$ and equipped with a field emission gun using low dose procedures [38].

\section{Circular dichroism spectroscopy}

A stock solution of $\mathrm{rSin} 1^{\text {lum }}$ was centrifuged (5 min, $20,000 \mathrm{~g})$ and diluted to $4 \mu \mathrm{M}$ using filtered $(0.2 \mu \mathrm{m}$ pore size) $10 \mathrm{mM}$ sodium phosphate $\mathrm{pH}$ 7.7. Spectra were acquired in a quartz cuvette with a thickness of $1 \mathrm{~mm}$ (110-1-P-40; Hellma Analytics) using a Chirascan-Plus CD spectrometer (Applied Photophysics) set to $25^{\circ} \mathrm{C}$ or $93{ }^{\circ} \mathrm{C}$. Measurement parameters were five accumulations per measurement, $260-190 \mathrm{~nm}$ wavelength range, $1 \mathrm{~nm}$ wavelength step size, $1 \mathrm{~nm}$ bandwidth, $0.5 \mathrm{~s}$ time per point. Raw spectra of $\mathrm{rSin} 1^{\text {lum }}$ were corrected by subtracting a spectrum of the buffer solution. Data were then transformed into the mean residue ellipticity (MRE, physical dimension: $\operatorname{deg} \mathrm{cm}^{2} \mathrm{dmol}^{-1}$ ) by applying the equation $\mathrm{MRE}=\theta \times 100 /(\mathrm{c} \times \mathrm{d} \times \mathrm{AA})$, where $\theta$ is the measured ellipticity (in degrees), $\mathrm{c}$ is the protein concentration (in dmol $\mathrm{mL}^{-1}$ ), $\mathrm{d}$ is the path length of the cuvette (in $\mathrm{cm}$ ), and $\mathrm{AA}$ is the number of amino acid residues in $\mathrm{rSin} 1^{\text {lum }}$. The transformed data (wavelength range $240-190 \mathrm{~nm}$ ) were then analyzed for secondary structure content using the DiChroWeb server [39, 40] and the CDSSTR method (reference data set 7 from taken from reference [41]).

\section{Ellman's assay for thiol groups}

The assay was performed following a protocol provided by the manufacturer of Ellman's reagent ( $5,5^{\prime}$-dithio-bis(2-nitrobenzoic acid, Thermo Scientific). Different concentrations of $\mathrm{rSin} 1^{\text {lum }}$ in $10 \mathrm{mM}$ sodium phosphate buffer pH 7.7 were mixed with $180 \mu \mathrm{M}$ Ellman's reagent followed by a $15 \mathrm{~min}$ incubation period and photometric detection at $412 \mathrm{~nm}$ using a plate reader (Biotek). Cysteine hydrochloride was used to generate a standard curve, which was then used to calculate the concentration of thiol groups in a given concentration of $\mathrm{rSin} 1^{\mathrm{lum}}$.

\section{Silica formation assay}

Stock solutions of rSin $1^{\text {lum }}$ and LCPA were diluted to a final concentration of $25 \mu \mathrm{M}$ in $50 \mathrm{mM}$ sodium acetate at $\mathrm{pH}$ 5.5. Where required, mixtures were supplemented with $30 \mathrm{mM}$ sodium phosphate-citrate at $\mathrm{pH}$ 5.5. Silicic acid was freshly prepared by hydrolysis of TMOS (1 M TMOS in $1 \mathrm{mM} \mathrm{HCl}, 15 \mathrm{~min}$ at room temperature under constant mixing) and added to the protein solutions at a final concentration of $100 \mathrm{mM}$. After $10 \mathrm{~min}$ incubation, the solutions were centrifuged $(5 \mathrm{~min}$, $16,000 \mathrm{~g}$ ) and the pellets were washed three times with $\mathrm{H}_{2} \mathrm{O}$ followed by centrifugation $(5 \mathrm{~min}, 16,000 \mathrm{~g}$ ). The final pellet was dissolved in $2 \mathrm{M} \mathrm{NaOH}\left(95{ }^{\circ} \mathrm{C}, 1\right.$ hour), and the silica concentration determined using the silicomolybdate assay [42].

\section{Expression of GFP-tagged $\operatorname{Sin} 1$ in T. pseudonana}

The start and stop codons of Sin 1 were confirmed by 5 and 3'-RACE PCR (Additional file 1: Figure S10, experimental details in Supporting Materials and Methods). Construction of the fusion genes encoding Sin1-GFP ${ }^{C}$ and Sin1-GFP ${ }^{\mathrm{N}}$ and their expression in T. pseudonana is described in Additional file 1: Supporting Materials and Methods.

\section{Expression of double-tagged $\operatorname{Sin} 1$ in T. pseudonana}

Construction of the $\operatorname{Sin} 1-\mathrm{mT}^{\mathrm{N}}{ }^{\mathrm{N}}$-Venus ${ }^{\mathrm{C}}$ fusion gene (mTurquoise2 located between the RXL and NQ-rich regions of the luminal domain and Venus located at the C-terminus of the cytosolic domain of Sin1) is described in Additional file 1: Supporting Materials and Methods. 
Fluorescence microscopy of biosilica and organic matrices Biosilica and insoluble organic matrices were isolated from T. pseudonana as described previously [17], and analyzed for GFP by epifluorescence microscopy using a $63 \times$ oil objective on a Zeiss Axiovert 200 inverted microscope equipped with a Piston filter (Chroma; excitation $450-490 \mathrm{~nm}$, emission $500-530 \mathrm{~nm}$ ).

\section{Confocal fluorescence microscopy of live cells}

For imaging, $10 \mu \mathrm{L}$ of a cell suspension was transferred onto a $22 \mathrm{~mm} \times 50 \mathrm{~mm}$ coverslip and covered with a rectangular slice $\left(\sim 0.5 \mathrm{~cm}^{2}\right)$ made of $1 \%(\mathrm{w} / \mathrm{v})$ agarose in EASW medium. Images were acquired using a Zeiss LSM780 inverted confocal microscope equipped with a Zeiss Plan-Apochromat 63× (1.4) Oil DIC M27 objective. GFP fluorescence and chlorophyll autofluorescence were detected in one-track mode using an Argon laser line (power set to $2 \%$ ), a MBS 488 beam splitter and a 32-channel GaAsP spectral detector. Two channels were acquired to separately monitor the GFP fluorescence (emission at 491-535 $\mathrm{nm}$ ) and chloroplast fluorescence (emission at 654-693 nm). Images of double-tagged Sin1 (Sin1-mT2 ${ }^{\mathrm{N}}$-Venus ${ }^{\mathrm{C}}$ ) were acquired using the $440 \mathrm{~nm}$ (for mTurquoise2) and $514 \mathrm{~nm}$ (for Venus and chloroplasts) laser lines set to laser intensities of $0.2 \%$ and $1 \%$, respectively. Three channels were acquired to separately monitor the fluorescence of mTurquoise2 (emission at $455-500 \mathrm{~nm}$ ), Venus (emission at 517$553 \mathrm{~nm}$ ) and chloroplast fluorescence (emission at 657$688 \mathrm{~nm}$ ). All images were analyzed using the ZEN2012 software (Zeiss).

For time-lapse imaging, equal volumes of a cell suspension and an approximately $30{ }^{\circ} \mathrm{C}$ solution of $1 \%$ $(\mathrm{w} / \mathrm{v})$ low-melting agarose (Fisher Scientific, USA) in EASW medium were gently mixed and transferred into a $35 \mathrm{~mm}$ diameter petri dish with a glass bottom $(1.5 \mathrm{H}$, $170 \pm 5 \mu \mathrm{m}$; Ibidi, Germany). To allow for gelation, the petri dish was incubated at $18{ }^{\circ} \mathrm{C}$ for $10 \mathrm{~min}$. When labeling with PDMPO (Biomol, Germany) was required, $190 \mu \mathrm{L}$ of $10 \mu \mathrm{M}$ PDMPO in EASW medium was mixed with $750 \mu \mathrm{L}$ cell suspension and the resulting suspension was mixed with $940 \mu \mathrm{L}$ of agarose as described above, yielding a gel with a final PDMPO concentration of $1 \mu \mathrm{M}$. After overlaying $2 \mathrm{~mL}$ of EASW medium on top of the agarose gel, the petri dish was sealed with Parafilm and incubated for approximately 2 hours at room temperature in the dark before mounting onto a microscope stage tempered at $17{ }^{\circ} \mathrm{C}$ (Thermal Insert and Liquid Cooling System from Warner Instruments, USA). Imaging was performed with an inverted IX81 microscope (Olympus, Japan) equipped with an UApochromat $60 \times 1.15 \mathrm{~W}$ air objective, ZDC hardware autofocus, NanoScanZ and ProScanIII xy scanning stages (Prior
Scientific), and diode $405 \mathrm{~nm}$, DPSS $488 \mathrm{~nm}$, and $561 \mathrm{~nm}$ lasers (Coherent). GFP (ex. $488 \mathrm{~nm}$, em. 525/ $30 \mathrm{~nm}$ bandpass), PDMPO (ex. $405 \mathrm{~nm}$, em. 525/30 nm bandpass), and chlorophyll autofluorescence (excitation $488 \mathrm{~nm}$, emission $568 \mathrm{~nm}$ longpass) were detected using a spinning disc Yokogawa CSU-X1 dichroic beam splitter (5000 rpm; Triple band T-405/488/561) and an iXon EM+ DU-897 BV back illuminated EMCCD camera (Andor, Oxford Instruments). For each experiment, a total of 15 agarose-embedded cells were selected for imaging. Each cell was exposed to LED brightfield light (50 ms) and then z-scanned $( \pm 2 \mu \mathrm{m}$ around the center of the cell with $0.5 \mu \mathrm{m}$ steps yielding $9 \mathrm{z}$-scans per cell per time point) with the following lasers in the order given: $488 \mathrm{~nm}$ (chlorophyll; laser power: $\sim 23 \mu \mathrm{W}$; $\mathrm{t}=$ $50 \mathrm{~ms}$ ), $488 \mathrm{~nm}$ (GFP; laser power: $\sim 115 \mu \mathrm{W} ; \mathrm{t}=$ $600 \mathrm{~ms}$ ), $405 \mathrm{~nm}$ (PDMPO; laser power: $\sim 37 \mu \mathrm{W} ; \mathrm{t}=$ $150 \mathrm{~ms})$. This procedure was subsequently repeated cell by cell. Cells were imaged in the same order in $3.5 \mathrm{~min}$ intervals for a total of 100 times. Labeling with $1 \mu \mathrm{M}$ Hoechst 34580 dye (Thermo Scientific, USA) was performed as described for PDMPO above, and imaged by exciting at $405 \mathrm{~nm}$ (laser power: $\sim 56 \mu \mathrm{W}, \mathrm{t}=150 \mathrm{~ms}$ ) and detecting emission at $445 \mathrm{~nm}$.

\section{Quantitative analysis of fluorescence intensities from time lapse imaging}

The raw movie files were analyzed using Fiji (Image), National Institute of Health) and Matlab R2016a (Mathworks). To examine valve biogenesis, live-cell imaging data of four cells were analyzed as follows. The raw movies were rotated and cropped to align the cells vertically. The intensities of all nine z-planes recorded were summarized for each frame yielding Fig. 5. The background was corrected by setting the global minimum fluorescence intensity outside the cell to zero. The movie was further processed in Matlab correcting for drift via a cross-correlation image registration [43]. The movie was then split into rectangular subregions as indicated in the corresponding figures. The region size was linearly interpolated between key frames to account for cell growth during the recording time. The fluorescence intensity was summarized for each region and frame, and plotted over time. The total fluorescence intensity prior to cytokinesis was normalized to 1.0 to allow for comparison of different cells. To build an average intensity plot of all cells, the peak intensity for PDMPO fluorescence was used for postsynchronization. Time-lapse data from four cells were used to generate an average fluorescence intensity plot.

\section{Preparation of membranes from T. pseudonana}

Total membranes were prepared according to a published protocol [21]. 
Carbonate extraction of total membranes from T. pseudonana Equal aliquots of freshly prepared membranes were resuspended in carbonate buffer $\left(0.1 \mathrm{M} \mathrm{NaHCO}_{3}, 1 \mathrm{mM}\right.$ EDTA, pH 11.5) or lysis buffer (50 mM Hepes, $150 \mathrm{mM}$ $\mathrm{NaCl}, 250 \mathrm{mM}$ sucrose, $\mathrm{pH}$ 7.5). All buffers contained one tablet of EDTA-free protease inhibitor (Pierce) per $10 \mathrm{~mL}$ of buffer. The membrane suspensions were incubated on ice for $45 \mathrm{~min}$, followed by centrifugation at $100,000 \mathrm{~g}$ for $60 \mathrm{~min}$. The supernatants were collected and the membrane pellets were resuspended in lysis buffer. Equal aliquots of supernatant and membrane pellet were analyzed by Western Blot using antibodies directed against rSin $1^{\text {lum }}$, PsbD, and AtpB (see below).

\section{HF treatment of membranes from T. pseudonana}

Membranes were freeze-dried, mixed with approximately $500 \mu \mathrm{L}$ anhydrous HF (GHC Gerling), and incubated on ice for $60 \mathrm{~min}$. The HF was removed by evaporation using a gentle stream of nitrogen followed by drying in a Speedvac. The residue was resuspended in $150 \mu \mathrm{L}$ lysis buffer (50 mM Hepes, $150 \mathrm{mM} \mathrm{NaCl}$, $250 \mathrm{mM}$ sucrose, $\mathrm{pH}$ 7.5) supplemented with 1\% Igepal, and immediately neutralized using $\mathrm{NH}_{4} \mathrm{OH}$. The suspension was mixed with sample loading solution and analyzed by Western blot using the anti-Sin 1 antibody as described below.

\section{Western blot analysis}

For SDS-PAGE aliquots of the solubilized membranes were mixed with sample loading buffer, incubated for $10 \mathrm{~min}$ at $95{ }^{\circ} \mathrm{C}$ or $60{ }^{\circ} \mathrm{C}$ (membrane containing samples), and centrifuged (5 min, 20,000 g) prior to loading on NuPAGE 4-12\% Bis-Tris SDSPAGs (Thermo Scientific). For Sin1, detection gels were wet-blotted onto Protran $0.45 \mu \mathrm{m}$ nitrocellulose membranes (GE Healthcare) and for PsbD and AtpB detection onto $0.45 \mu \mathrm{m}$ PVDF membranes (Immobilon-P, Millipore) using Towbin buffer (25 mM Tris, $192 \mathrm{mM}$ glycine) supplemented with $20 \% \quad(\mathrm{v} / \mathrm{v})$ methanol. The blots were blocked with $2 \%(\mathrm{w} / \mathrm{v})$ albumin fraction $\mathrm{V}$ (Merck Millipore) dissolved in TBST (50 mM Tris, $150 \mathrm{mM} \mathrm{NaCl}, 0.05 \%$ (v/v) Tween-20 (Biorad), pH 7.5). After 60 min incubation at room temperature, the blots were washed three times for $10 \mathrm{~min}$ with $20 \mathrm{~mL}$ TBST. The blots were then incubated with the desired antibodies diluted in TBST (1:10,000 anti-rSin1 $1^{\text {lum }}$ antiserum, 1:2500 anti-PsbD and anti-AtpB antibodies). After $60 \mathrm{~min}$ incubation at room temperature, the blots were washed three times for $10 \mathrm{~min}$ with $20 \mathrm{~mL}$ TBST and subsequently incubated with anti-rabbit IgG (Sigma) dissolved in TBST at a dilution of 1:10,000. After $60 \mathrm{~min}$ incubation at room temperature, the blots were washed twice in $20 \mathrm{~mL}$ TBST and twice in $20 \mathrm{~mL}$ TBS (i.e., TBST without Tween-20). Excess buffer was removed from the blots using paper towels before incubating with $2 \mathrm{~mL}$ SuperSignal West Pico chemiluminescent substrate (Thermo Scientific) for $5 \mathrm{~min}$ at room temperature. Chemiluminescence was detected using the ChemiDoc MP imaging system (Biorad).

\section{Antibody accessibility experiments}

Quantification of the accessibility of Sin 1 in biosilica and organic matrices from Sin1-GFP ${ }^{\mathrm{N}}$-expressing transformants was performed with a 1:1000 dilution of the anti-Sin 1 antiserum using a previously published method [17]. The method is described in detail in Additional file 1: Supporting Materials and Methods.

\section{Immunodetection of GFP in biosilica and insoluble organic matrices}

Immunolabeling of biosilica and organic matrices from wild-type cells and transformants expressing Sin1GFP $^{\mathrm{C}}$ or Sin1-GFP ${ }^{\mathrm{N}}$ was carried out using an anti-GFP antibody as described in Additional file 1: Supporting Materials and Methods.

\section{Bioinformatics analysis}

The genomes of the diatoms C. cryptica [44], T. oceanica [45], and F. cylindrus [46] are publically available from the UCSC genome browser, the NCBI database, and the JGI database, respectively. Transcriptome databases for other diatom and non-diatom organisms were downloaded from the Marine Microbial Eukaryote Transcriptome Sequencing Project [18] (MMETSP; current number of entries in the re-assembled database used: 659; download link: https://monsterbashseq.wordpress.com/2016/09/13/mmetsp-re-assemblies/). The Sin1 (T. pseudonana) protein sequence was used to perform a tBlastn search against the respective databases (Matrix: Blosum62, Gap Penalties: Existence: 11, Extension: 1, Neighboring words threshold: 13, Window for multiple hits: 40). BLAST hits with an E-value of lower than approximately $1 \times 10^{-50}$ were considered Sin 1 homologous proteins, accounting for 70 unique diatom species and two non-diatom species out of the 659 entries in the MMETSP. Protein sequences of Sin 1 homologues were extracted from the translated transcriptome databases for the two non-diatom species and three species each from centric diatoms and pennate diatoms that showed the lowest E-values. These protein sequences were then used to calculate sequence identities to Sin1 and to prepare the accompanying sequence alignment in 
Additional file 1: Figure S1. Blast searches were also performed using the genome of Amphimedon queenslandica [20], which is available at the NCBI database, and the transcriptomes of Haliclona amboinensis and Ephydatia muelleri, which are both available at http:// www.compagen.org.

\section{Additional files}

Additional file 1: Figure S1. Sequence conservation of silicanins in diatoms and other protists. Figure S2. DNA and amino acid sequences of $\mathrm{rSin} 1^{-\mathrm{SP}}$ and $\mathrm{rS} \operatorname{Sin} 1^{\mathrm{lum}}$, Figure S3. Membrane association of $\operatorname{Sin} 1$. Figure S4. Accessibility of Sin 1 in biosilica and organic matrices. Figure S5. Localization of a double-tagged $\operatorname{Sin} 1$ fusion protein ( $\operatorname{Sin} 1-\mathrm{mT}^{\mathrm{N}}-\mathrm{Venus}^{\mathrm{C}}$ ) in T. pseudonana. Figure S6. Anti-GFP immunolabeling of biosilica and organic matrices isolated from T. pseudonana transformant cells expressing $\operatorname{Sin} 1-G F P^{C}$ or $\operatorname{Sin} 1-G F P^{N}$. Figure S7. Time-lapse imaging of a live cell around the time of nuclear division. Figure $\mathbf{S 8}$. Time-dependent quantitative analysis of region-specific GFP fluorescence during girdle band formation in a $\operatorname{Sin} 1-G F P^{C}$ expressing cell. Figure S9. Biochemical analysis of $r \operatorname{Sin} 1^{\text {lum }}$. Figure S10. DNA sequences obtained from 5'- and 3'-RACE PCR analysis of Sin1 mRNA. Table S1. $\operatorname{Sin} 1$ homologues identified through tBLASTn searches. Table S2. Sequence identities between T. pseudonana (Tps) Sin1 and Sin2, and between homologues from other diatoms and non-diatom organisms. Table S3. Quantification of the extractability of Sin 1, PsbD, and AtpB from T. pseudonana membranes. Table S4. Quantification of the accessibility of Sin 1 in biosilica. Table S5. Secondary structure analysis of rSin1 1um. Table S6. Determination of free sulfhydryl groups in rSin1 ${ }^{\text {lum }}$. (PDF $1979 \mathrm{~kb}$ )

Additional file 2: Movie S1. Time-lapse imaging of a $\sin 1-G F P C$ expressing live cell around the time of valve biogenesis. (AVI $21692 \mathrm{~kb}$ ) Additional file 3: Movie S2. Time-lapse imaging of a live-cell around the time of nuclear division. (AVI $21692 \mathrm{~kb}$ )

Additional file 4: Movie S3. Time-lapse imaging of a live cell around the time of girdle band biogenesis. (AVI $7201 \mathrm{~kb}$ )

\section{Abbreviations}

BLAST: basic local alignment search tool; DLS: dynamic light scattering; EASW: enriched artificial sea water; EDTA: ethylenediamine tetraacetic acid; GFP: enhanced green fluorescent protein; LCPA: long-chain polyamines; MMETSP: Marine Microbial Eukaryote Transcriptome Sequencing Project; MRE: mean residue ellipticity; mT2: mTurquoise2; PAGE: polyacrylamide gel electrophoresis; PDMPO: 2-(4-pyridyl)-5-((4-(2-

dimethylaminoethylaminocarbamoyl)methoxy)phenyl)oxazole; SDS: Sodium dodecylsulfate; SDV: silica deposition vesicle; Sin1: Silicanin-1;

TMOS: tetramethoxysilane

\section{Acknowledgements}

We thank Julia Palm, Anke Borrmann, and Martina Lachnit (all B CUBE, TU Dresden) for expert technical assistance, Britta Schroth-Diez and Bert Nitzsche (Light microscopy facility, MPI-CBG, Dresden), and the CMCB Light Microscopy Facility (TU Dresden) for help with confocal microscopy. We are grateful to Andrew Alverson (University of Arkansas) for performing the BLAST search of Sin 1 against the MMETSP database, and to Nicole Poulsen for critically reading the manuscript.

\section{Funding}

This work was supported by the Deutsche Forschungsgemeinschaft through Research Unit 2038 "NANOMEE" (DFG grants KR 1853/6 and SCHL 1896/2), by the German Federal Ministry of Education and Research BMBF (grant 03Z2EN11 to M.S.), by the European Union (EFRE), and by the Free State of Saxony (SMWK).

\section{Availability of data and materials}

Transcriptome data used for the bioinformatics analysis of $\operatorname{Sin} 1$ are available at http://marinemicroeukaryotes.org/and http://www.compagen.org/ index.html. All other data used in this study are part of this published article and its supplementary information files.

\section{Authors' contributions}

NK and AK designed the study. AK, DP and PB performed the experiments, All authors analyzed data and interpreted results. NK wrote the manuscript. NK and AK edited the manuscript. All authors reviewed the results and approved the final version of the manuscript.

Ethics approval and consent to participate Not applicable.

\section{Consent for publication}

Not applicable.

\section{Competing interests}

The authors declare that they have no competing interests.

\section{Publisher's Note}

Springer Nature remains neutral with regard to jurisdictional claims in published maps and institutional affiliations.

\section{Author details}

${ }^{1} B$ CUBE Center for Molecular Bioengineering, CMCB, TU Dresden, Arnoldstrasse 18, 01307 Dresden, Germany. ${ }^{2}$ Department of Chemical Engineering and Chemistry, Laboratory of Materials and Interface Chemistry \& Center of Multiscale Electron Microscopy, P.O. Box 513, 5600 MB Eindhoven, The Netherlands. ${ }^{3}$ institute for Complex Molecular Systems, Eindhoven University of Technology, P.O. Box 513, 5600 MB Eindhoven, The Netherlands. ${ }^{4}$ Department of Chemistry and Food Chemistry, TU Dresden, 01062 Dresden, Germany .

Received: 18 May 2017 Accepted: 28 June 2017

Published online: 24 July 2017

\section{References}

1. Hildebrand M, Lerch SJ. Diatom silica biomineralization: Parallel development of approaches and understanding. Semin Cell Dev Biol. 2016;46:27-35.

2. Kröger N, Brunner E. Complex-shaped microbial biominerals for nanotechnology. WIREs Nanomed Nanobiotechnol. 2014;6:615-27.

3. Lowenstam HA, Weiner S. On Biomineralization. Oxford: Oxford University Press; 1989.

4. Bäuerlein E. Biomineralization of unicellular organisms: an unusual membrane biochemistry for the production of inorganic nano- and microstructures. Angew Chem Int Ed. 2003;42:614-41.

5. Weiner S, Addadi L. Crystallization pathways in biomineralization. Annu Rev Mater Res. 2011:41:21-40.

6. Zurzolo C, Bowler C. Exploring bioinorganic pattern formation in diatoms: a story of polarized trafficking. Plant Physiol. 2001;127:1339-45.

7. Pickett-Heaps J, Schmid AMM, Edgar LA. The cell biology of diatom valve formation. In: Progress in Phycological Research Vol. 7. Round FE, Chapman DJ, eds. Bristol: Biopress; 1990. p. 1-169.

8. Tanaka A, De Martino A, Amato A, Montsant A, Mathieu B, Rostaing P, Tirichine L, Bowler C. Ultrastructure and membrane traffic during cell division in the marine pennate diatom Phaeodactylum tricornutum. Protist. 2015;166:506-21.

9. van de Meene AML, Pickett-Heaps JD. Valve morphogenesis in the centric diatom Proboscia alata Sundstrom. J Phycol. 2002;38:351-563.

10. Tesson B, Hildebrand M. Extensive and intimate association of the cytoskeleton with forming silica in diatoms: control over patterning on the meso- and micro-scale. PLoS One. 2010;5:e14300.

11. Tesson B, Hildebrand M. Dynamics of silica cell wall morphogenesis in the diatom Cyclotella cryptica: substructure formation and the role of microfilaments. J Struct Biol. 2010;169:62-74.

12. Robinson DH, Sullivan CW. How do diatoms make silicon biominerals? Trends Biochem Sci. 1987;12:151-4.

13. Kröger N, Poulsen N. Diatoms - from cell wall biogenesis to nanotechnology. Annu Rev Genet. 2008;42:83-107.

14. Poulsen N, Kröger N. Silica morphogenesis by alternative processing of silaffins in the diatom Thalassiosira pseudonana. J Biol Chem. 2004;279:42993-9.

15. Wenzl S, Hett R, Richthammer P, Sumper M. Silacidins: Highly acidic phosphoproteins from diatoms shells assist in silica precipitation in vitro. Angew Chem Int Ed. 2008;47:1729-32. 
16. Scheffel A, Poulsen N, Shian S, Kröger N. Nanopatterned protein microrings from a diatom that direct silica morphogenesis. Proc Natl Acad Sci U S A. 2011;108:3175-80.

17. Kotzsch A, Pawolski D, Milentyev A, Shevchenko A, Scheffel A, Poulsen N, Shevchenko A, Kröger N. Biochemical composition and assembly of biosilica-associated insoluble organic matrices from the diatom Thalassiosira pseudonana. J Biol Chem. 2016;291:4982-97.

18. Keeling PJ, et al. The Marine Microbial Eukaryote Transcriptome Sequencing Project (MMETSP): illuminating the functional diversity of eukaryotic life in the oceans through transcriptome sequencing. PLoS Biol. 2014;12:e1001889.

19. Durak GM, Taylor AR, Walker CE, Probert I, de Vargas C, Audic S, Schroeder D, Brownlee C, Wheeler GL. A role for diatom-like silicon transporters in calcifying coccolithophores. Nat Commun. 2016;7:10543.

20. Srivasta M, et al. The Amphimedon queenslandica genome and the evolution of animal complexity. Nature. 2010;466:720-6.

21. Sheppard VC, Poulsen N, Kröger N. Characterization of an endoplasmic reticulum-associated silaffin kinase from the diatom Thalassiosira pseudonana. J Biol Chem. 2010;285:1166-76.

22. Mort AJ, Lamport DTA. Anhydrous hydrogen fluoride deglycosylates glycoproteins. Anal Biochem. 1977;82:289-309.

23. Fujiki Y, Hubbard AL, Fowler S, Lazarow PB. Isolation of intracellular membranes by means of sodium carbonate treatment: application to endoplasmic reticulum. J Cell Biol. 1982;93:97-102.

24. Miller JD, Tajima S, Lauffer $L$, Walter $P$. The $\beta$ subunit of the signal recognition particle receptor is a transmembrane GTPase that anchors the a subunit, a peripheral membrane GTPase, to the endoplasmic reticulum membrane. J Cell Biol. 1995;128:273-82.

25. Schieweck O, Damme M, Schröder B, Hasilik A, Schmidt B, Lübke T. NCU-G1 is a highly glycosylated integral membrane protein of the lysosome. Biochem J. 2009:422:83-90.

26. Shimizu K, Del Amo Y, Brzezinski MA, Stucky GD, Morse DE. A novel fluorescent silica tracer for biological silicification studies. Chem Biol. 2001;8:1051-60.

27. Vrieling EG, Gieskes WWC, Beelen TPM. Silicon deposition in diatoms: control by the $\mathrm{pH}$ inside the silicon deposition vesicle. J Phycol. 1999:35:548-59.

28. Parambath M, Hanley QS, Martin-Martinez FJ, Giesa T, Buehler MJ, Perry CC. The nature of the silicaphilic fluorescence of PDMPO. Phys Chem Chem Phys. 2016;18:5938-48.

29. Hildebrand M, Kim S, Shi D, Scott K, Subramaniam S. 3D imaging of diatoms with ion-abrasion scanning electron microscopy. J Struct Biol. 2009;166:316-28.

30. Dill KA, Ghosh K, Schmit JD. Physical limits of cells and proteomes. Proc Natl Acad Sci U S A. 2011;108:17876-82.

31. Gordon R, Drum RW. The chemical basis of diatom morphogenesis. Int Rev Cytol. 1994;150:243-372

32. Kröger N, Lorenz S, Brunner E, Sumper M. Self-assembly of highly phosphorylated silaffins and their function in biosilica morphogenesis. Science. 2002;298:584-6.

33. Poulsen N, Sumper M, Kröger N. Biosilica formation in diatoms: characterization of native silaffin-2 and its role in silica morphogenesis. Proc Natl Acad Sci U S A. 2003:100:12075-80.

34. Lee RE. Phycology. Cambridge: Cambridge University Press; 2008.

35. Hibberd DJ, Chretiennot-Dinet M-J. The ultrastructure and taxonomy of Rhizochromulina marina gen. et ap. nov., an amoeboid marine chrysophyte. J Marine Assoc U K. 1979:59:179-93.

36. Sandgren CD, Smol JP, Kristiansen J. Chrysophyte Algae: Ecology, Phylogeny, and Development. Cambridge: Cambridge University Press; 1995.

37. Chen X, Gao S, Liu W, Song W, Al-Rasheid KAS, Warren A. Taxonomic descriptions of three marine colepid ciliates, Nolandia sinica spec. nov., Apocoleps caoi spec nov. and Tiarina fusa (Claparéde \& Lachmann, 1858) Bergh, 1881 (Ciliophora, Prorodontida). Int J Syst Evol Microbiol. 2012;62:735-44.

38. Friedrich $H$, Frederik PM, de With G, Sommerdijk NAJM. Imaging of selfassembled structures: interpretation of TEM and cryo-TEM images. Angew Chem Int Ed. 2010:49:7850-8.

39. Whitmore L, Wallace BA. Protein secondary structure analyses from circular dichroism spectroscopy: methods and reference databases. Biopolymers. 2008:89:392-400

40. Whitmore L, Wallace BA. DICHROWEB, an online server for protein secondary structure analyses from circular dichroism spectroscopic data. Nucleic Acids Res. 2004;32:W668-73.

41. Sreerama N, Woody RW. Estimation of protein secondary structure from CD spectra: Comparison of CONTIN. SELCON and CDSSTR methods with an expanded reference set. Anal Biochem. 2000;287:252-60.
42. $\quad$ ler RK. The Chemistry of Silica. New York: Wiley; 1979.

43. Guizar-Sicairos M, Thurman ST, Fienup JR. Efficient subpixel image registration algorithms. Opt Lett. 2008;33:156-8.

44. Traller JC, et al. Genome and methylome of the oleaginous diatom Cyclotella cryptica reveal genetic flexibility toward a high lipid phenotype. Biotechnol Biofuels. 2016:9:258.

45. Lommer M, et al. Genome and low-iron response of an oceanic diatom adapted to chronic iron limitation. Genome Biol. 2012;13:R66.

46. Mock T, et al. Evolutionary genomics of the cold-adapted diatom Fragilariopsis cylindrus. Nature. 2017;541:536-40.

47. Petersen TN, Brunak S, von Heijne G, Nielsen H. SignalP 4.0: discriminating signal peptides from transmembrane regions. Nat Methods. 2011;8:785-6.

48. Krogh A, Larsson B, von Heijne G, Sonnhammer ELL. Predicting transmembrane protein topology with a hidden Markov model: Application to complete genomes. J Mol Biol. 2001;305:567-80.

\section{Submit your next manuscript to BioMed Central and we will help you at every step:}

- We accept pre-submission inquiries

- Our selector tool helps you to find the most relevant journal

- We provide round the clock customer support

- Convenient online submission

- Thorough peer review

- Inclusion in PubMed and all major indexing services

- Maximum visibility for your research

Submit your manuscript at www.biomedcentral.com/submit
) Biomed Central 